\title{
CXCR4 activation maintains a stem cell population in tamoxifen-resistant breast cancer cells through AhR signalling
}

\author{
A Dubrovska*,1,3 , A Hartung ${ }^{2,4}$, LC Bouchez ${ }^{1,5}$, JR Walker², VA Reddy ${ }^{2,6}$, CY Cho ${ }^{2}$ and PG Schultz ${ }^{*, 1}$ \\ 'Department of Chemistry, The Scripps Research Institute, 10550 North Torrey Pines Road, La Jolla, CA 92037, USA; ${ }^{2}$ Genomics Institute of the Novartis \\ Research Foundation, 10675 John Jay Hopkins Drive, San Diego, CA 92121 , USA
}

\begin{abstract}
BACKGROUND: Tamoxifen is commonly used for breast cancer therapy. However, tamoxifen resistance is an important clinical problem. Continuous treatment with conventional therapy may contribute to cancer progression in recurring cancers through the accumulation of drug-resistant cancer progenitors.

METHODS: To investigate signalling mechanisms important for the maintenance and viability of drug-resistant cancer progenitors, we used microarray analysis, PCR array for genes involved in cancer drug resistance and metabolism, flow cytometry, soft agar colony formation assay, in vivo tumourigenicity assay and immunohistochemical analysis using tamoxifen-sensitive and tamoxifen-resistant breast cancer MCF7 cells.

RESULTS: Downregulation of CXCR4 signalling by small molecule antagonist AMD3I00 specifically inhibits growth of progenitor cell population in MCF7(TAM-R) cells both in vitro and in vivo. Microarray analysis revealed aryl hydrocarbon receptor (AhR) signalling as one of the top networks that is differentially regulated in MCF7(TAM-R) and MCF7 xenograft tumours treated with AMD3I00. Further, small molecule antagonists of AhR signalling specifically inhibit the progenitor population in MCF7(TAM-R) cells and growth of MCF7(TAM-R) xenografts in vivo.

CONCLUSION: The chemokine receptor CXCR4 maintains a cancer progenitor population in tamoxifen-resistant MCF7 cells through AhR signalling and could be a putative target for the treatment of tamoxifen-resistant breast cancers.

British Journal of Cancer (2012) 1 07, 43-52. doi:I0.1038/bjc.2012.105 www.bjcancer.com
\end{abstract}

Published online 29 May 2012

(C) 2012 Cancer Research UK

Keywords: tamoxifen resistance; cancer progenitors; CXCR4; AhR

Targeting the oestrogen signalling pathway dramatically improves long-term disease-free and overall survival for women with hormone receptor-positive breast cancer. Tamoxifen, a triphenylethylene-selective oestrogen receptor modulator, is currently the most widely used hormonal treatment for breast cancer. The antiproliferative activity of tamoxifen relies primarily on its ability to compete with oestrogen for the oestrogen receptor (ER) ligandbinding site in breast tumour tissue (Dhingra, 1999; Lin et al, 2010). When effective, tamoxifen produces objective tumour shrinkage in advanced breast cancer, reduces the risk of relapse in women treated for invasive breast cancer, and prevents breast cancer in high-risk women. However, only $40-50 \%$ of patients with ER-positive breast cancer benefit from tamoxifen treatment, and many acquire resistance, leading to breast tumour growth

\footnotetext{
*Correspondence: Dr A Dubrovska or Professor PG Schultz; E-mail: anna.dubrovska@oncoray.de or schultz@scripps.edu

${ }^{3}$ Current address: OncoRay - National Center for Radiation Research in Oncology, Medical Faculty Dresden Carl Gustav Carus, TU Dresden, Fetscherstr. 74/ PF4I, 01307 Dresden

${ }^{4}$ Current address: Allergan, Inc, 2525 Dupont Dr, Irvine, CA 92612 USA

${ }^{5}$ Current address: Novartis Institutes for BioMedical Research, Basel, Switzerland

${ }^{6}$ Current address: Sanofi-Aventis U.S, Cambridge, MA, USA

Received 28 November 2011; revised 24 February 2012; accepted 6 March 2012; published online 29 May 2012
}

and secondary malignancies like uterine cancers (Normanno et al, 2005).

One possible explanation for the initial positive response to therapy followed by drug-resistant disease is that whereas current therapies eliminate the bulk of the tumour they fail to eliminate cancer stem cells (CSC). In fact, it has been argued that many cancers are maintained in a hierarchical organisation of rare CSC and differentiated tumour cells; the CSC are not only the renewable source of tumour cells but also of tumour resistance leading to tumour recurrence, metastasis and tumour progression (O'Brien et al, 2009; Rosen and Jordan, 2009). Support for this hypothesis came with the identification of tumour-initiating cells in leukaemia, and subsequently in a variety of cancers including solid tumours. In addition, cancer cell lines have been shown to harbour progenitor stem cells, and are a promising model for cancer stem cell research because these progenitors can be readily expanded and analysed (Charafe-Jauffret et al, 2009; HwangVerslues et al, 2009).

Recently, a successful cell culture model of tamoxifen resistance has been created by in vitro selection of a tamoxifen-resistant cell line (TAM-R), derived from endocrine-sensitive wild-type MCF7 human breast cancer cells (Hutcheson et al, 2003; Fan et al, 2006). The development of in vitro model of tamoxifen resistance provides a potentially useful tool for the identification of novel signalling mechanisms important for maintenance and viability of drug-resistant cancer progenitors.

Our study suggests that TAM-R cells have a larger cancer progenitor population compared with wild-type breast cancer 
cells, an intriguing observation given the aggressiveness of tamoxifen-resistant tumours. Moreover, we have found that the cancer progenitor population in TAM-R cells is sensitive to CXCR4 signalling, and demonstrated that TAM-R tumour growth is inhibited by CXCR4 inhibition in vivo. Finally, microarray analysis of progenitor populations indicates that the transcription factor aryl hydrocarbon receptor (AhR) also has an important role in the CSC phenotype. Taken together, these data suggest a novel nexus of CXCR4 and AhR signalling that regulates tumourigenicity in the tamoxifen-resistant context.

\section{MATERIALS AND METHODS}

\section{Cells and reagents}

Tamoxifen-sensitive MCF7 cells and 4-hydroxytamoxifen-resistant MCF7(TAM-R) cells were obtained from Dr Kenneth P. Nephew (Indiana University) and maintained as described (Fan et al, 2006). The cells were grown in phenol red-free DMEM medium supplemented with $10 \%$ charcoal-stripped fetal bovine serum (FBS). The antibodies used were: CXCR4 (ab2074, Abcam, Cambridge, UK); $\beta$-actin (mAb, Sigma Aldrich, St Louis, MO, USA); ABCG2 (sc-58222, Santa Cruz Biotechnology, Santa Cruz, CA, USA), rabbit IgG, HRP-linked whole Ab, mouse IgG, and HRP-linked whole $\mathrm{Ab}$ (GE Healthcare, Piscataway, NJ, USA). The CXCR4 antagonist AMD3100, 4-hydroxytamoxifen and 3-methylcholanthrene were purchased from Sigma Aldrich. $\mathrm{CH} 223191$ was purchased from Tocris Bioscience (Ellisville, MO, USA). SR1 and SR2 compounds were prepared as described (Bouchez et al, 2011).

\section{Cancer drug resistance and metabolism PCR array}

Before all experiments, MCF7 and MCF7(TAM-R) cells were cultured in growth medium (minimum essential medium with $2 \mathrm{mmol}$ per 1 L-glutamine, $0.1 \mathrm{mmol}$ per 1 non-essential amino acids, 50 units $\mathrm{ml}^{-1}$ penicillin, $50 \mathrm{mg} \mathrm{ml}^{-1}$ streptomycin, $6 \mathrm{ng} \mathrm{ml}^{-1}$ insulin, and $10 \% \mathrm{FBS}$ ) in the absence of 4-hydroxytamoxifen for 7 days. Total RNA was isolated from cell pellets using the RNeasy kit (Qiagen, Valencia, CA, USA). Reverse transcription was performed using High Capacity cDNA Reverse Transcription Kit (Applied Biosystems, Carlsbad, CA, USA). The Human Cancer Drug Resistance and Metabolism PCR Array (SuperArray, Frederick, MD, USA) was used to identify genes involved in tamoxifen resistance in MCF7 breast cancer cells. The data analysis was performed using the PCR Array Data Analysis Web Portal (SuperArray).

\section{Side population (SP) analysis and Aldefluor assay}

For flow cytometry, $1 \times 10^{6}$ cells were dissociated with Accutase (Innovative Cell Tech Inc., San Diego, CA, USA) and incubated in pre-warmed DMEM/5\% FBS containing freshly added Hoechst $33342\left(5 \mu \mathrm{g} \mathrm{ml}^{-1}\right.$ final concentration) for $90 \mathrm{~min}$ at $37^{\circ} \mathrm{C}$ with intermittent mixing. In some experiments, cells were incubated with the Hoechst dye in the presence of verapamil $\left(50 \mu \mathrm{moll}^{-1}\right)$. At the end of incubation, cells were spun down at $4{ }^{\circ} \mathrm{C}$ and resuspended in ice-cold PBS. 7-AAD $\left(2 \mu \mathrm{g} \mathrm{ml}^{-1}\right.$ final concentration) was added for 5 min before flow cytometry analysis, which allows for the discrimination of dead $v s$ live cells. Samples were analysed on a BD LSR II flow cytometer (Becton Dickinson Immunocytometry Systems, San Jose, CA, USA). The Aldefluor kit (Stem Cell Technologies, Vancouver, BC, Canada) was used to identify cell populations with high aldehyde dehydrogenases $(\mathrm{ALDH})$ enzymatic activity. Briefly, cells were incubated in Aldefluor assay buffer containing ALDH substrate $\left(1 \mu \mathrm{moll} 1^{-1}\right.$ per $1 \times 10^{6}$ cells). In each experiment, a sample of cells was stained under identical conditions with $50 \mathrm{mmoll}^{-1}$ of diethylaminobenzaldehyde, a specific ALDH inhibitor, as negative control. Following $30 \mathrm{~min}$ incubation at $37^{\circ} \mathrm{C}$, the cells were centrifuged, resuspended in cold Aldefluor buffer and stained with $1 \mu \mathrm{g} \mathrm{ml}^{-1} 4^{\prime}$,6-diamidino-2-phenylindole (Sigma-Aldrich) to discriminate viable cells from dead cells during the following analysis on BD LSRII (Becton Dickinson Immunocytometry Systems).

\section{Soft agar colony formation assay}

To examine anchorage-independent growth, a cell suspension (500 cells $\mathrm{ml}^{-1}$ ) in $0.2 \%$ low-melting SeaPlaque CTG agarose (Cambrex Bio Science Rockland, Inc., Rockland, ME, USA) with growth medium was overlaid into 24 -well plates containing a $0.5 \%$ agar base. All samples were plated in octuplicates. The plates were incubated at $37^{\circ} \mathrm{C}$ in a humidified incubator for 14 days.

\section{In vivo tumourigenicity assay}

Ovariectomised 5-6-week-old nu/nu athymic nude mice were obtained from Jackson Laboratories (Bar Harbor, ME, USA) and maintained under standard conditions according to Institutional Animal Care guidelines. The research protocol was approved by the Institutional Animal Care and Use Committee of the Genomics Institute of the Novartis Research Foundation, and meets the standards required by UKCCCR guidelines. All surgery was performed under sodium pentobarbital anaesthesia, and all efforts were made to minimise suffering. MCF7(TAM-R) and MCF7 xenograft tumours were established in mice supplemented with $0.25 \mathrm{mg} 21$-day release oestrogen pellets by inoculating subcutaneously $10^{6}$ cells in BD Matrigel Basement Membrane Matrix (BD Biosciences, Mountain View, CA, USA). When tumours reached the size of $150-200 \mathrm{~mm}^{3}$ (3-5 weeks), the animals were randomly allocated to continued oestrogen and oestrogen withdrawal plus tamoxifen citrate $(500 \mu \mathrm{g}$ per animal given subcutaneously in peanut oil, 5 days per week), alone or in combination with the small molecule CXCR4 antagonist AMD3100. To ensure consistent levels of the antagonist throughout the experimental period, we used osmotic Alzet pumps (Alza Corporation, Palo Alto, CA, USA) to deliver AMD3100 at a constant rate of $0.25 \mu \mathrm{g} \mathrm{kg}^{-1}$ $\mathrm{h}^{-1}$. The pumps loaded with AMD3100 or saline were implanted subcutaneously.

\section{Microarray analysis}

Three pooled tumours per each treatment condition were isolated on the fourteenth day of the treatment and snap-frozen for RNA isolation, gene expression analysis and validation study. Microarray analysis was carried out as described earlier (Dubrovska et al, 2009). Briefly, total RNA was isolated from cell pellets using the RNeasy kit (Qiagen). Sample preparation for GeneChip analysis was carried out according to the protocol detailed by Affymetrix (Santa Clara, CA, USA). Briefly, first and second cDNA strands were synthesised; double stranded cDNA was in vitro transcribed using the Affymetrix $3^{\prime}$ amplification kit; and the resulting cRNA was purified, fragmented and hybridised to oligonucleotide arrays (Human Genome U133 Plus 2.0 Array, catalogue number 900467, http://www.Affymetrix.com) representing $>47000$ transcripts. Arrays were processed using standard Affymetrix protocols. The Affymetrix Hybridization Control Kit and Poly-A RNA control kit were used for hybridisation. Probe values from CEL files were condensed to probe sets using the gcRMA package from Bioconductor (http://www.bioconductor. org) and the $\mathrm{R}$ programme ( $\mathrm{R}$ Development Core Team, 2004). The data set was unlogged and median scaled to a target intensity of 100. Primer sets used for microarray validation shown in Supplementary Table 3. 


\section{Statistical analysis}

The results of soft agar colony formation assays, flow cytometry analysis, cell proliferation assays, and in vivo tumourigenicity assays were analysed by paired $t$-test. A $P$ value of $<0.05$ was regarded as statistically significant.

Table I List of genes involved in tamoxifen resistance in MCF7 breast cancer cells identified in The Human Cancer Drug Resistance and Metabolism PCR Array (SuperArray) (the data analysis was performed using the PCR Array Data Analysis Web Portal (SuperArray))

\begin{tabular}{lcc}
\hline Gene symbol & $\begin{array}{l}\text { Fold up- or downregulation; } \\
\text { MCF7 (TAM-R) /MCF7 }\end{array}$ & t-test \\
\hline ABCG2 & 2.410 & 0.011 \\
ABCBI - 8.690 .034 & -8.690 & 0.034 \\
ABCC6 - 2.030 .027 & -2.030 & 0.027 \\
CYPIAI -4.28 0.004 & -4.280 & 0.004 \\
NAT2 -9.08 0.045 & -9.080 & 0.045 \\
NFKBIE 3.28 0.04 & 3.280 & 0.040 \\
SULTIEI - |46.49 0.002 & -146.490 & 0.002 \\
\hline
\end{tabular}

\section{RESULTS}

\section{ABCG2 is overexpressed in tamoxifen-resistant MCF7 breast cancer cells}

To identify the molecular mechanisms of resistance to tamoxifen in MCF7 breast cancer cells, we investigated the expression profiles of genes involved in drug resistance and metabolism with a Human Cancer Drug Resistance and Metabolism PCR Array (SuperArray). In all, 7 of the 84 genes exhibited more than a twofold difference in expression level in the MCF7 and MCF7(TAM-R) cell lines (Table 1). These genes include adenosine triphosphate-binding cassette (ABC) transporters such as ABCB1, ABCC6, and ABCG2 that modulate intracompartmental and intracellular concentrations of chemotherapeutic drugs (Dean, 2009), CYP1A1, NAT2, SULT1E1 that regulate oestrogen and xenobiotic metabolism (Rebbeck et al, 2007; Delort et al, 2010), and NFKB1E known to be linked to the aetiology and progression of hormone-independent breast cancers (Zhou et al, 2005). The ATP-binding cassette transporter ABCG2 is a marker for the SP enriched in cancer progenitors (Lou and Dean, 2007). This cell population expresses high levels of $\mathrm{ABC}$ transporters, providing a high level of drug resistance. Tamoxifen-resistant MCF7(TAM-R) cells showed an increased level of ABCG2 expression as analysed by RT-PCR and western blot analysis (Figure 1A). Our data suggest
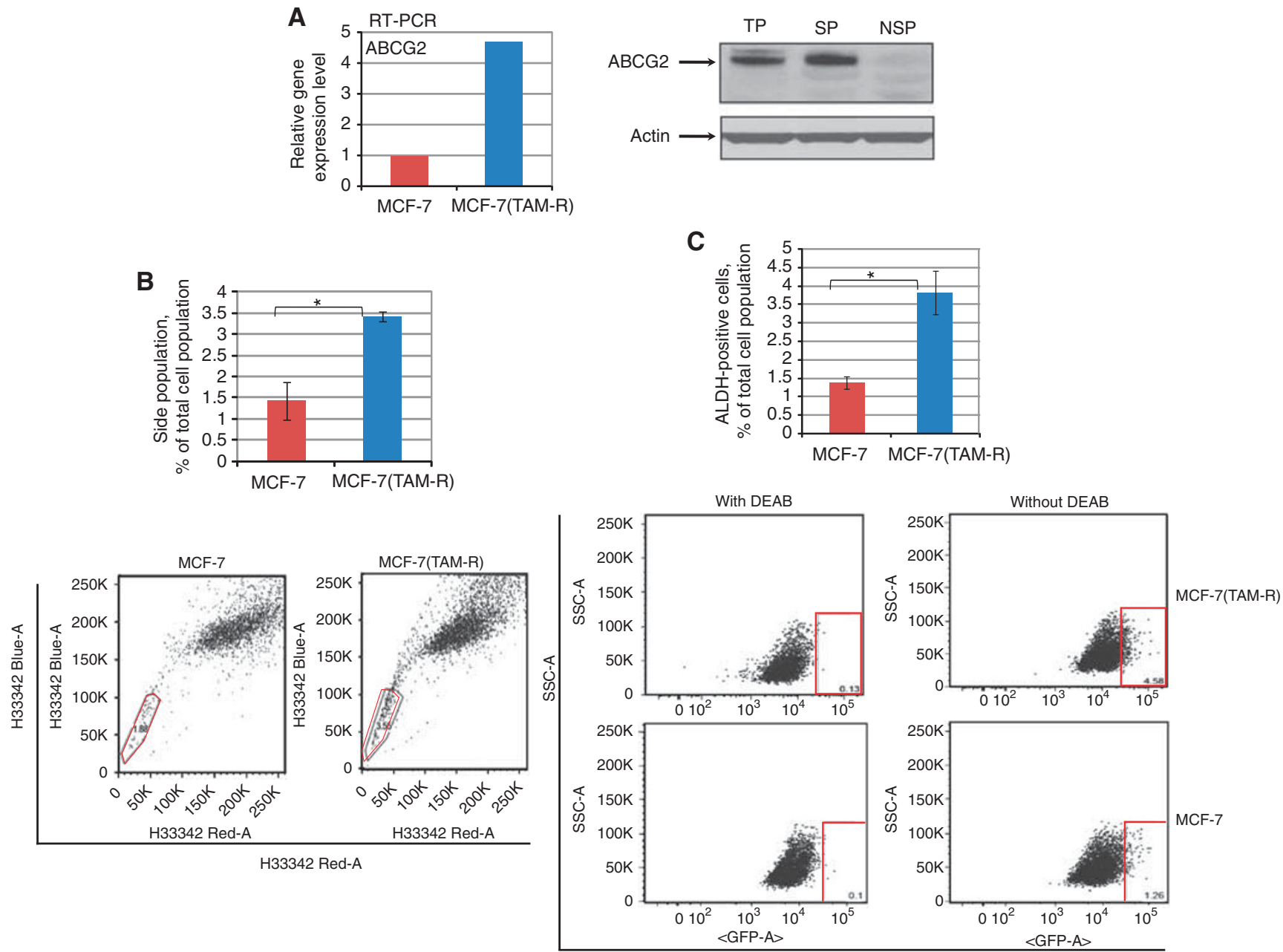

GFP

Figure I High expression level of ABCG2 in tamoxifen-resistant MCF7 cells line is associated with an increase in the cancer progenitor population. (A) MCF7(TAM-R) cells showed an increased level of ABCG2 expression as analysed by RT-PCR and western blot analysis. (B) Side population analysis and $(\mathbf{C})$ Aldefluor assay showed a significant enrichment of the progenitor population within MCF7(TAM-R) cells compared with the tamoxifen-sensitive MCF7 cells (*P value $<0.05)$. 
that tamoxifen resistance may be associated with an increase in the population of ABCG2-positive tumour-initiating cells.

\section{Tamoxifen-resistant cells have a higher percentage of cancer progenitor cells that are responsive to CXCR4 inhibition}

The SP technique is the most widely used strategy to identify stemlike cell populations in vitro. The SP is a Hoechst dye-effluxing cell subset that has been identified in many human tissues and cell lines (Hadnagy et al, 2006; Engelmann et al, 2008; Wu and Alman, 2008; Charafe-Jauffret et al, 2009). The property of SP cells to efflux lipophilic fluorescent dyes is based on their ability to preferentially express drug-efflux pumps such as ABCG2 (Doyle and Ross, 2003). Active drug efflux by ABCG2 is one of the most common mechanisms causing multiple drug resistance in various human cancers (Doyle and Ross, 2003; Lou and Dean, 2007). We found that MCF7(TAM-R) cells showed a significantly higher level of SP than tamoxifen-sensitive MCF7 cells (a 2.4-fold increase), (Figure 1B, Supplementary Figure S1A). Alternatively, we identified progenitor population by the enzymatic Aldefluor assay. Previous studies suggest that high ALDH activity identifies the tumourigenic cell fraction that is capable of self-renewal and generating xenograft tumours (Ginestier et al, 2007). We found a significantly higher ALDH activity in MCF7(TAM-R) cells as compared with tamoxifen-sensitive MCF7 cells (a 2.9-fold increase) (Figure 1C).

As expected, an increase in SP and Aldefluor-positive cell population in MCF7(TAM-R) cells correlated with a higher clonogenic potential (Supplementary Figure S1B) and tumourigenicity in vivo compared with MCF7 cells (Supplementary Figure S1C). PI3K, CXCR4 and GSK3 pathways are known to be involved in the regulation of progenitor population and drug sensitivity in breast cancers (Zhou et al, 2007; Hwang-Verslues et al, 2009; Korkaya et al, 2009; Huang et al, 2010). We analysed whether the chemical modulation of PI3K, CXCR4 and GSK pathways could regulate tamoxifen-resistant MCF7 progenitor cells. We found that Akt inhibitor IV $\left(\mathrm{IC}_{50}=1.94 \times 10^{-7}\right)$ and CXCR4 antagonist AMD3100 $\left(\mathrm{IC}_{50}=2.55 \times 10^{-7}\right)$ are potent inhibitors of SP in tamoxifen-resistant MCF7(TAM-R) cells (Figure 2A). Although previous studies implicate an important role for Akt kinase in the development of tamoxifen resistance and regulation of breast CSC (Clark et al, 2002), little is known about the role of CXCR4 pathway in the maintenance of tamoxifen-resistant cancer progenitors. Our data suggest that MCF7(TAM-R) cells are more sensitive to negative modulation of CXCR4 signalling than MCF7 cells (Figure $2 \mathrm{~B}$ and $\mathrm{C}$ ) and tamoxifen-resistant progenitor cell population could be specifically inhibited by CXCR4 antagonist AMD3100 in a dose-dependent manner (up to 2.2-fold decrease) (Figure 2D). These results suggest a role of CXCR4 in the maintenance of tamoxifen-resistant cancer progenitors.

\section{Inhibition of CXCR4 reduces tamoxifen-resistant tumour cell growth and alters AhR signalling}

Sensitivity of MCF7(TAM-R) and parental MCF7 cells to CXCR4 inhibition was analysed in vivo using mouse MCF7(TAM-R) and MCF7 xenograft models. Our data suggest that the MCF7(TAM-R) xenograft tumours treated with the CXCR4 inhibitor AMD3100 showed more than a twofold decrease in the growth rate compared with a control group (Figure $3 \mathrm{~A}$ ). Interestingly, the tamoxifensensitive xenograft tumours did not show significant growth inhibition in response to AMD3100 treatment (Figure 3B). Haematoxylin and eosin staining of the xenografts confirmed regression of MCF7(TAM-R) tumours in AMD3100-treated animals (Figure 3C). ABCG2 expression is known to be preferentially upregulated in the stem-like cell compartment, suggesting a role of ABCG2 in protecting this population against chemotherapy (Doyle and Ross, 2003; Lou and Dean, 2007). Histological analysis of MCF7(TAM-R) xenograft tumours treated with AMD3100 revealed a decrease in ABCG2 expression as compared with untreated MCF7(TAM-R) xenografts and tumours formed by MCF7 cells (Figure 3D).

Thus, we have shown that CXCR4-directed therapy specifically targets cancer progenitor population in tamoxifen-resistant MCF7 cells in vitro and in vivo. To understand the molecular mechanisms underlying selective sensitivity of tamoxifen-resistant cancer stem-like cell population to CXCR4 inhibition, MCF7 (TAM-R) and MCF7 xenografts tumours harvested after the treatment with CXCR4 antagonist AMD3100 were used for microarray analysis of gene expression using Affymetrix U133 arrays (Supplementary Table S1 and S2). Gene expression analysis revealed 2759 genes showing $\geqslant 3.5$-fold changes in expression level in MCF7(TAM-R) tumours treated with AMD3100 in combination with tamoxifen as compared with tamoxifen-sensitive MCF7 xenografts exposed to the same conditions. An overlay of canonical pathways identified p53 signalling, glucocorticoid receptor, ERK-MAPK, oestrogen receptor, integrin signalling, retinoid acid receptor activation, gonadotropin-releasing hormone, and aryl hydrocarbon receptor (AhR) signalling as top ten networks that are disregulated in MCF7(TAM-R) tumours as compared with MCF7 xenograft tumours. Notably, AhR signalling was more disturbed in tamoxifen-resistant MCF7 xenograft tumours treated with AMD3100 in combination with both tamoxifen and oestrogen as compared with tamoxifen-sensitive MCF7 xenografts treated in the same manner (Supplementary Figure S2). The RT-PCR analysis confirmed that genes TP53, FOS, PERG, SMARCA4 and HSP90AA1 that are involved in AhR signalling network are similarly downregulated in MCF7(TAM-R) tumours treated with CXCR4 inhibitor AMD3100 and tamoxifen, and upregulated in MCF7 tamoxifen-sensitive tumours under the same treatment conditions (Figure $3 \mathrm{E}$ and $\mathrm{F}$ ). Oestrogen receptor alpha physically interacts with AhR and regulates AhR-dependent gene transcription. The data from microarray analysis suggest that transcription of ESR1 gene has a very similar trend to the regulation of few other genes involved in AhR signalling pathway (Supplementary Figure S3). Our data suggest that the chemokine receptor CXCR4 has a role in tumourigenicity of tamoxifenresistant breast cancer cells via regulation of AhR transactivation.

\section{AhR signalling differentially regulates MCF7(TAM-R) and MCF7 cells.}

Aryl hydrocarbon receptor (AhR) is a nuclear receptor mediating biological responses to aromatic hydrocarbons. Recent experimental evidences suggest that $\mathrm{AhR}$ has an important role in immune system function and for regulation of other nuclear receptors and transcription factors, including ER (36). AhR could interact with ER machinery by different mechanisms including competing for common cofactors, regulation of the oestrogen level by controlling the gene expression of CYPs, increase of proteasome-dependent ER degradation, and competing for promoter binding (Duan et al, 1999; Finlin et al, 2001; Pocar et al, 2005; Swedenborg and Pongratz, 2010). Recent data suggest that normal and cancer human mammary epithelial cells with increased aldehyde dehydrogenase activity have stem/progenitor properties (Ginestier et al, 2007; Hwang-Verslues et al, 2009).

Analysis of tumour gene expression in 88 breast cancer patients treated with tamoxifen demonstrated that $\mathrm{ER} \beta$ protein is predictor of tamoxifen response in a large patient set, including both ER $\alpha$-positive and ER $\alpha$-negative tumours treated with tamoxifen for 2 years (Gruvberger-Saal et al, 2007). ER $\alpha$ expression was significantly associated with a better prognosis exclusively within the ER $\beta$-negative tumours. Analysis of $A H R$ gene expression in this patient set was performed using publicly available microarray data set GDS2827 from National Center for Biotechnology 

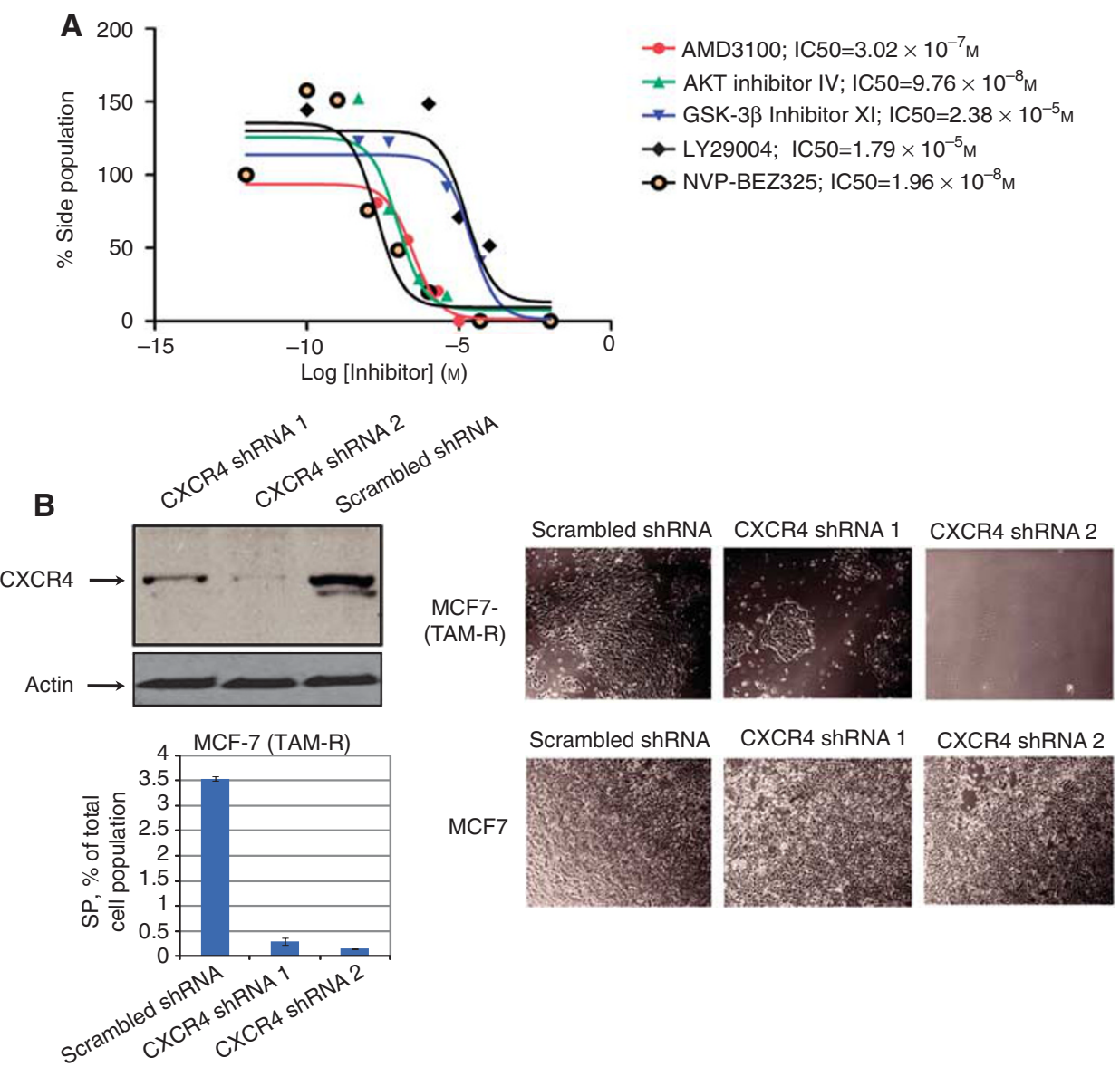

C
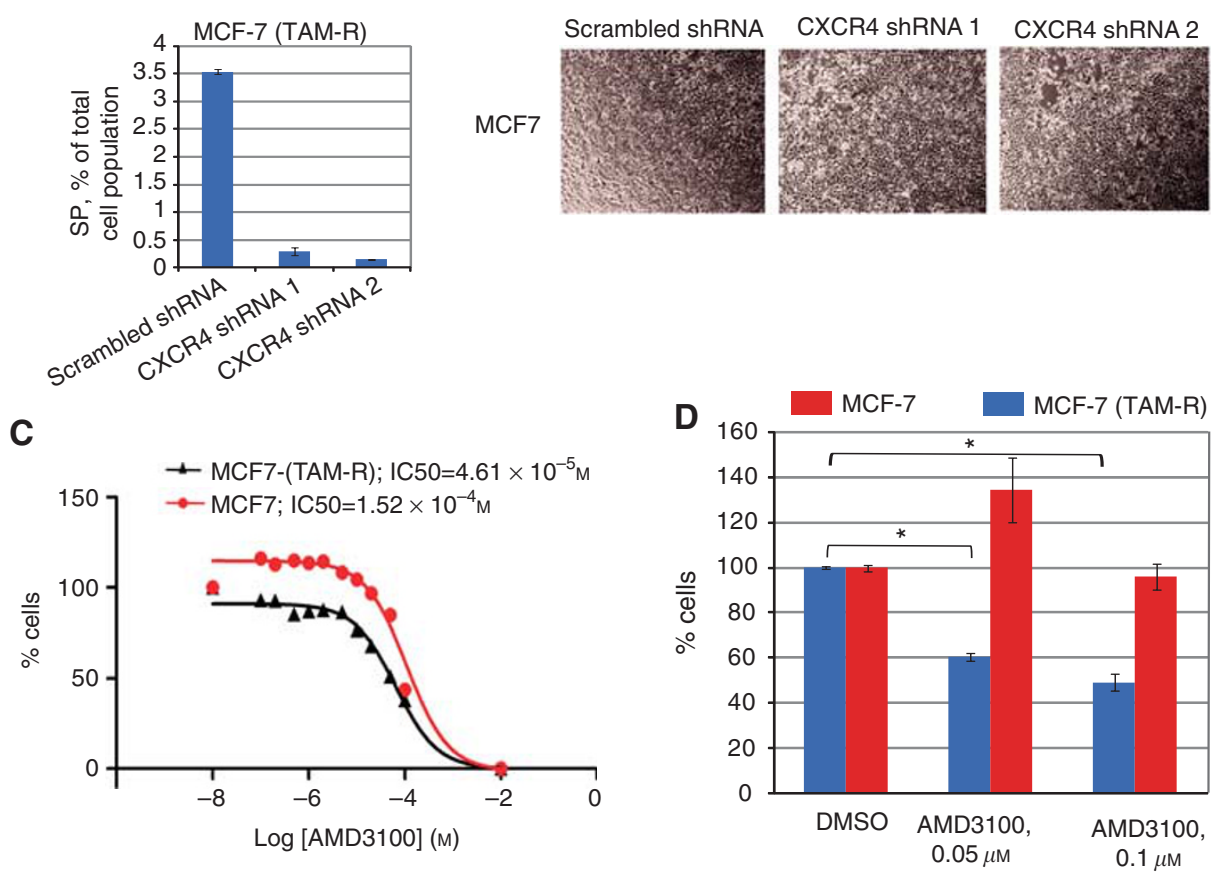

Figure 2 MCF7(TAM-R) cells are more sensitive to modulation of CXCR4 signalling than MCF7 cells and tamoxifen-resistant progenitor cell population, and could be specifically inhibited by CXCR4 antagonist AMD3I00. (A) AKT inhibitor IV $\left(\mathrm{C}_{50}=1.94 \times 10^{-7}\right)$ and CXCR4 antagonist AMD3I00 $\left(\mathrm{IC}_{50}=2.55 \times 10^{-7}\right)$ are potent inhibitors of SP in tamoxifen-resistant cell. MCF7(TAM-R) cells were cultured in tamoxifen-free growth medium in the presence of inhibitors at indicated concentration for 5 days. The culture medium was replenished daily. (B) The CXCR4 knockdown in MCF7(TAM-R) cells showed a decrease in the SP and growth inhibition compared with scrambled shRNA-transduced control MCF7(TAM-R) cells. (C) MCF7(TAM-R) cells are more sensitive to modulation of CXCR4 signalling than MCF7 cells. The cells were cultured in tamoxifen-free growth medium in the presence of inhibitors at indicated concentration for 5 days. The culture medium was replenished daily. (D) The CXCR4 antagonist AMD3I00 specifically inhibits SP in the tamoxifen-resistant MCF7(TAM-R) cells in a dose-dependent manner. The cells were cultured in tamoxifen-free growth medium in the presence of inhibitors at indicated concentration for 3 days. The culture medium was replenished daily.

Information Gene Expression Omnibus. Interestingly, AHR gene expression was significantly inversely correlated with ER $\alpha$ expression only in the ER $\beta$-negative subgroup $(P<0.001)$, suggesting that $\mathrm{AhR}$ could be used as an additional marker predictive of treatment failure (Supplementary Figure S4).

We showed that small molecule antagonists of AhR signalling SR1, SR2 and CH-223191 (Figure 4A) can specifically inhibit ALDH-positive MCF7(TAM-R) cells and induce ALDH-positive population in MCF7 cells (Figure 4B and C). Alternatively, AhR agonist 3-methylchloroanthrene specifically increases ALDH population in MCF7 (TAM-R) cells, however does not affect or even decrease ALDH population in tamoxifen-sensitive MCF7 cells (Figure 4D). The previous studies of biological networks regulated by AhR signalling demonstrated that as a biological target, AhR was best predicted by lymphocyte antigen 6e (LY6E) expression (Johnson et al, 2004). Lymphocyte antigen 6e gene is known to promote breast cancer lung metastasis and is downregulated by aromatase inhibitor treatment in primary breast tumours, indicating a role of $\mathrm{AhR}$ signalling in these mechanisms (Mackay, et al, 2007; Dydensborg, et al, 2009). AhR antagonists 
A

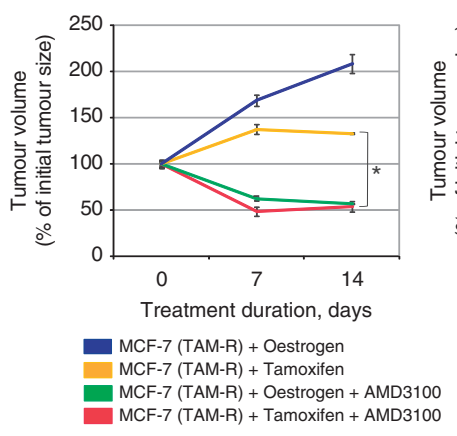

C

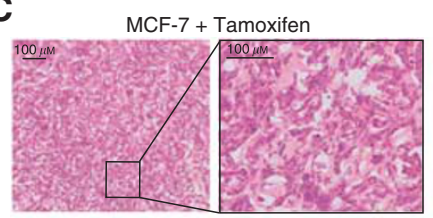

MCF-7 (TAM-R) + Tamoxifen

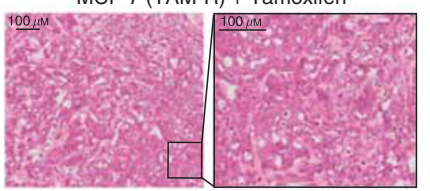

B

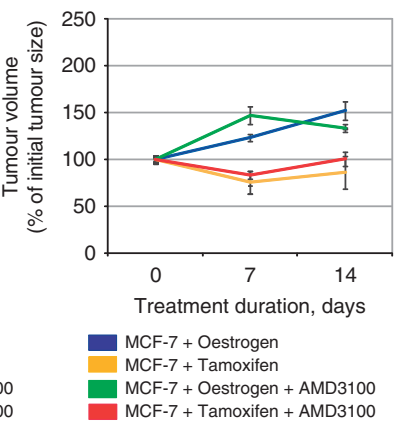

MCF-7 + Tamoxifen + AMD3100

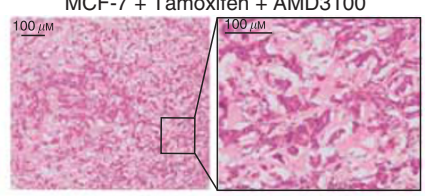

MCF-7 (TAM-R) + Tamoxifen + AMD3100

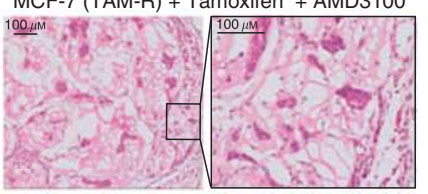

D

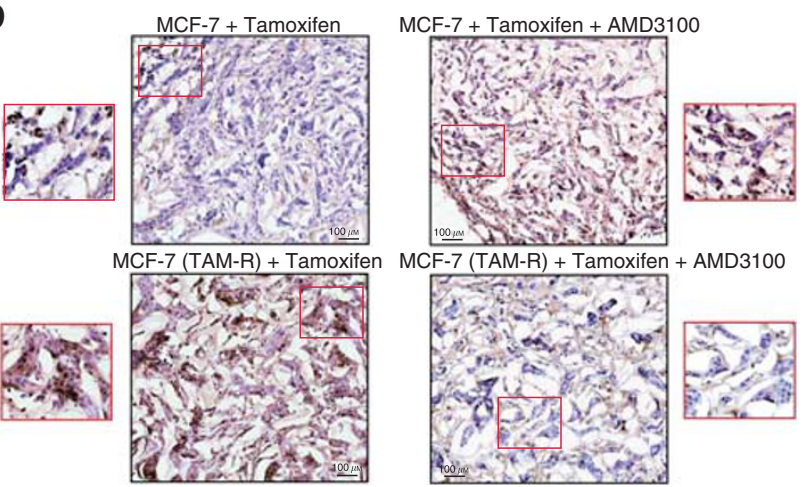

E

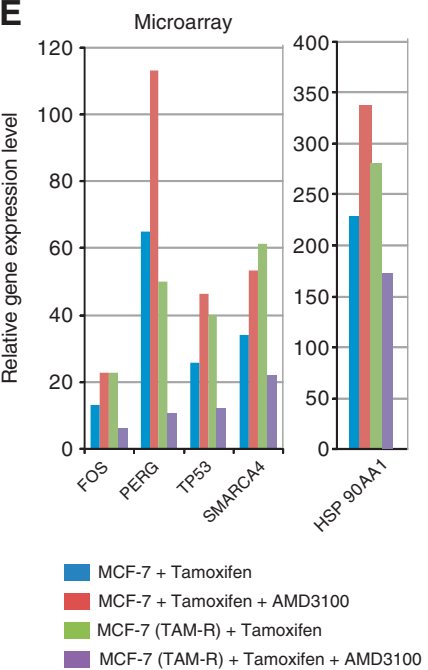

F

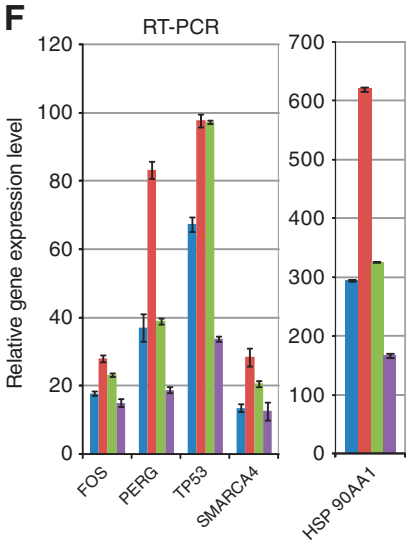

MCF-7 + Tamoxifen

MCF-7 + Tamoxifen + AMD3100 MCF-7 (TAM-R) + Tamoxifen

MCF-7 (TAM-R) + Tamoxifen + AMD3100

Figure 3 Inhibition of CXCR4 reduces tamoxifen-resistant tumour growth in vivo and alters AhR signalling. (A) MCF7(TAM-R) xenograft tumours treated with AMD3100 showed more than a twofold decrease in the growth rate compared with a control group. (B) The tamoxifen-sensitive xenograft tumours did not show a significant growth inhibition in response to AMD3 I00 treatment. (C) Haematoxylin and eosin staining of the xenografts showed regressive MCF7(TAM-R) tumours in AMD3100-treated animals. Two histological sections of two different tumours were analysed for each treatment condition. Representative images are showed. (D) Histological analysis of MCF7(TAM-R) xenograft tumours treated with AMD3 I 00 revealed a decrease in ABCG2 expression as compared with untreated MCF7(TAM-R) xenografts and tumours formed by MCF7 cells. (E) Gene expression analysis revealed the aryl hydrocarbon receptor signalling in top ten networks that are deregulated in MCF7(TAM-R) tumours as compared with MCF7 xenograft tumours. TP53, FOS, PERG, SMARCA4 and HSP9OAA I genes that are involved in AhR signalling network are similarly downregulated in MCF7(TAM-R) tumours treated with CXCR4 inhibitor AMD3IO0 and tamoxifen and upregulated in MCF7 tamoxifen-sensitive tumours under the same treatment conditions. (F) Microarray results were validated by RT-PCR analysis.

SR1 and SR2 specifically increase AhR-dependent expression of LY6E in tamoxifen-sensitive MCF7 cells but not in MCF7(TAM-R) cells (Figure 4E). Preincubation of MCF7(TAM-R) cells with small molecule antagonists of AhR signalling SR2 before subcutaneous injection into nude mice significantly delayed tumour growth (Figure 4F), compared with MCF7(TAM-R) xenografts treated with PBS or MCF7 xenografts treated with AhR antagonist. To identify the putative molecular targets of $A h R$ inhibition that are differentially regulated in MCF7(TAM-R) and MCF7 cells, we investigated the expression of 84 genes known to be involved in drug resistance with a Human Cancer Drug Resistance and Metabolism PCR Array (SuperArray). Five of them exhibited more than a twofold difference in expression level in the MCF7(TAM-R) and MCF7 cells in response to treatment with AhR antagonist $\mathrm{CH}-223191$ (Supplementary Figure S5). Interestingly, the genes identified in this array are functionally related to the genes responsible for tamoxifen-resistant phenotype and include regulators of oestrogen metabolism (CYP2C19, CYP2C8), member of $\mathrm{NF} \kappa \mathrm{B}$ family RELB, and $\mathrm{ABC}$ transporter ABCC2. The basic fibroblast growth factor-2 (FGF-2) was the highest upregulated gene in the MCF7(TAM-R) cells treated with AhR antagonist (more than threefold). In contrast, FGF-2 was downregulated in MCF7 cells in response to $\mathrm{CH}-223191$ treatment (more than twofold). Previous studies showed that a high level of FGF-2 expression downregulates Bcl-2, promotes apoptosis in MCF7 human breast cancer cells, induces differentiation in T-47D breast cancer cells and is associated with improved overall and disease-free survival in breast cancer patients (Yiangou et al, 1997; Maloof et al, 1999). Our results suggest that AhR signalling could be a putative target for the treatment of tamoxifen-resistant breast cancers based on the fact that AhR antagonists specifically inhibit the cancer progenitor population in tamoxifen-resistant MCF7 cells, and AhR signalling regulates genes that are involved in breast tumour progression and drug resistance.

\section{DISCUSSION}

Development of oestrogen independence and progression to a metastatic phenotype are hallmarks of therapeutic resistance and poor survival of breast cancer patients (Normanno et al, 2005). The CXCR4/CXCL12 axis is one of the key regulators of metastasis development and drug resistance in breast cancer (Darash-Yahana et al, 2004; Epstein, 2004; Vandercappellen et al, 2008, Zlotnik, 
A<smiles>CC(C)n1cnc2c(NCCc3ccc(O)cc3)nc(-c3csc4ccccc34)nc21</smiles>

B

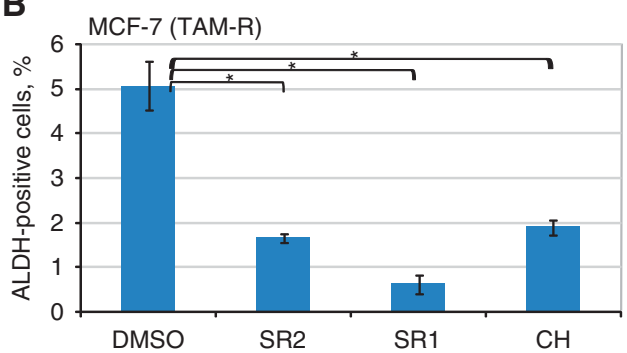<smiles>CCn1c(C)nc2cc(C(=O)Nc3ccccc3)ccc21</smiles>

SR2
C

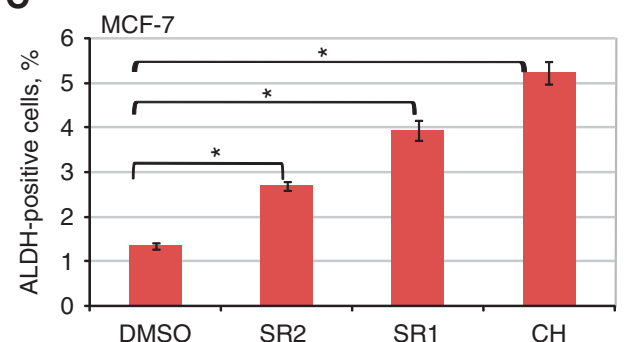

\section{D}

MCF-7

MCF-7 (TAM-R)

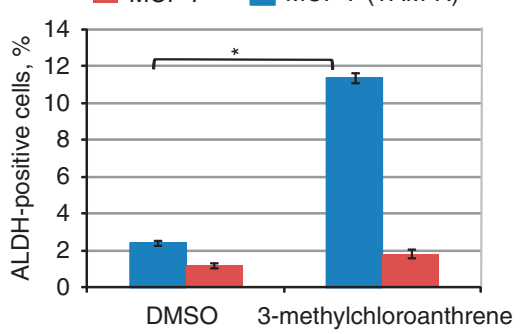

E 6

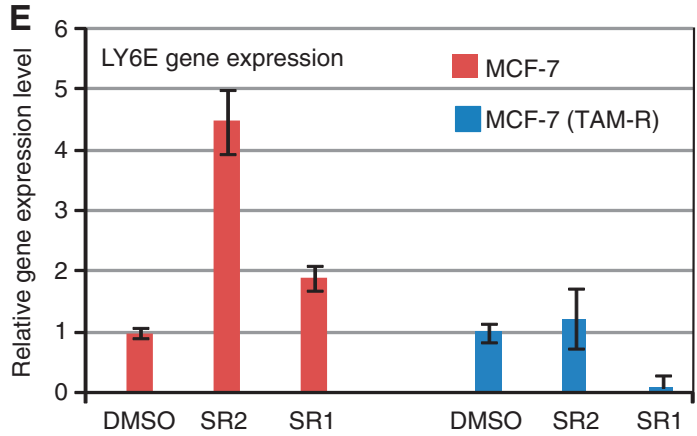

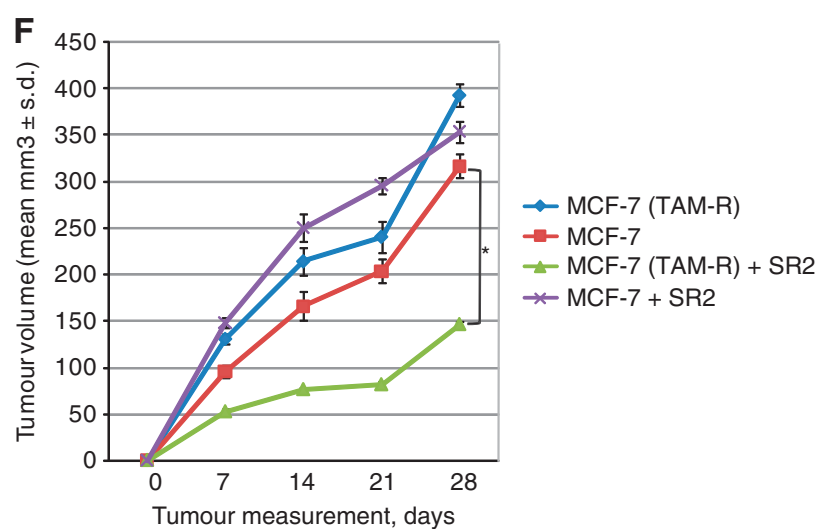

Figure 4 AhR signalling differentially regulates MCF7(TAM-R) and MCF7 cells. (A) Structure of AhR antagonists SRI and SR2. (B) Small molecule antagonists of AhR signalling SRI, SR2 and CH-223I I I could specifically inhibit ALDH-positive MCF7(TAM-R) cells and induce ALDH-positive population in MCF7 cells, (C). The cells were cultured in tamoxifen-free growth medium in the presence of SRI, SR2 and CH-223I9 Iat concentration I $\mu \mathrm{M}, 3 \mu \mathrm{M}$ and $3 \mu \mathrm{M}$, respectively for 5 days. The culture medium was replenished daily. (D) AhR agonist methylchloroanthrene specifically increases ALDH population in MCF7(TAM-R) cells. The cells were cultured in tamoxifen-free growth medium in the presence of methylchloroanthrene at concentration $5 \mu \mathrm{M}$ for 5 days. The culture medium was replenished daily. (E) AhR antagonists SRI and SR2 specifically increase AhR-depedent expression of LY6E gene in tamoxifensensitive MCF7 cells. (F) Preincubation of MCF7(TAM-R) cells with small molecule antagonists of AhR before subcutaneous injection into nude mice significantly delayed tumour growth compared with MCF7 (TAM-R) xenografts treated with DMSO or MCF7 xenografts treated with AhR antagonist. The cells were cultured in tamoxifen-free growth medium in the presence of SR2 at concentration $3 \mu \mathrm{M}$ or DMSO for 5 days. The culture medium was replenished daily.

2008; Furusato et al, 2010). Moreover, recent data suggest that enhanced CXCR4 signalling is sufficient to drive ER-positive breast cancers to a metastatic and endocrine therapy-resistant phenotype
(Rhodes et al, 2011). It has been argued that tumour progenitor cells have a crucial role in tumour development and represent a drug-resistant cell population that can survive conventional 
treatment, including hormonal therapy, and lead to tumour relapse (O'Brien et al, 2009; Rosen and Jordan, 2009). However, little is known about the molecular mechanisms regulating cancer progenitor cells in a drug-resistant context. The capacity to extrude Hoechst dye has been used to identify breast cancer stemlike cells called SP (Doyle and Ross, 2003; Hadnagy et al, 2006; Lou and Dean, 2007; Engelmann et al, 2008; Wu and Alman, 2008). This property of SP cells is based on their ability to preferentially express ABC transporter ABCG2 (Doyle and Ross, 2003). Recent data indicate that the ability of malignant SP cells to efflux cytostatic drugs may directly improve their survival and maintain their clonogenic properties during treatment with anticancer drugs (Dean, 2009).

Indeed, we found that MCF7(TAM-R) cells showed a significantly higher level of SP than tamoxifen-sensitive MCF7 cells. Our studies suggest that inhibition of CXCR4 with small molecule antagonists specifically target cancer stem-like cell populations in MCF7(TAM-R) cell line and could be beneficial for treatment of tamoxifen-resistant breast cancers. To our knowledge, our work is the first to characterise an increase in the progenitor population in tamoxifen-resistant cells and identify their distinct molecular nature by their differential response to CXCR4 inhibitors.

The cell surface chemokine CXCL12 (SDF-1) and its receptor CXCR4 were first identified as regulators of trafficking and homoeostasis of lymphocytes (Burger et al, 1999). Subsequently, CXCR4 has been proposed to regulate trafficking and invasion of breast cancer cells to sites of metastases (Epstein, 2004). More recently, it has been established that CXCR4 has a central role in cancer dissemination, invasion and proliferation in $>75 \%$ of cancers, including the breast, ovarian, lung, colon, prostate, kidney, melanoma, brain, oesophageal, pancreatic, and many forms of leukaemia (Darash-Yahana et al, 2004; Vandercappellen et al, 2008, Zlotnik, 2008; Furusato et al, 2010).

Blocking CXCR4 receptor function by a monoclonal antibody inhibits cancer cell proliferation and invasion in multiple preclinical models both in vitro and in vivo (Pan et al, 2006; Zeng et al, 2006). According to the stem cell model of cancer development, a distinct subpopulation of cancer stem-like cells initiates metastasis and renders the tumour resistant to chemotherapy. The fact that CXCR4 is present in normal and cancer stem-like cells in various tissues suggests that this molecule could be essential for maintenance and viability of the tumour progenitor cell population. Moreover, activation of CXCR4 axis is attributed to the development of drug resistance in gastric and pancreatic cancers and leukaemia (Zeng et al, 2006; Singh et al, 2010; Xie et al, 2010).

To understand the molecular mechanisms underlying selective sensitivity of tamoxifen-resistant cancer stem-like cell population to CXCR4 inhibition, MCF7(TAM-R) and MCF7 xenografts tumours treated with CXCR4 antagonist AMD3100 were used for microarray analysis. To shed light on the signalling pathways that are differentially regulated in tamoxifen-sensitive and tamoxifenresistant cell lines, all 2759 differentially expressed genes were subjected to Ingenuity pathway analysis. An overlay of canonical pathways identified AhR signalling as one of the top 10 networks, which was represented by 19 genes, including FOS, RERG, SMARCA4, HSP90AA1, and TP53.

It has been reported that AhR nuclear translocation could induce p53-dependent transcription of the murine multidrugresistance gene $M D R-1$ (Mathieu et al, 2001). $M D R-1$ gene is highly expressed in cancer progenitor cells and can determine multidrug resistance in this cell population (Bunting, 2002; Hadnagy et al, 2006) that could explain why tamoxifen-resistant cancer progenitors are highly dependent on AhR transactivation. AhR also regulates ER-dependent transcription of FOS protooncogene (Hennessy et al, 2005), RARG growth inhibitory gene and HSP90AA1 gene that have been implicated in modulating steroid

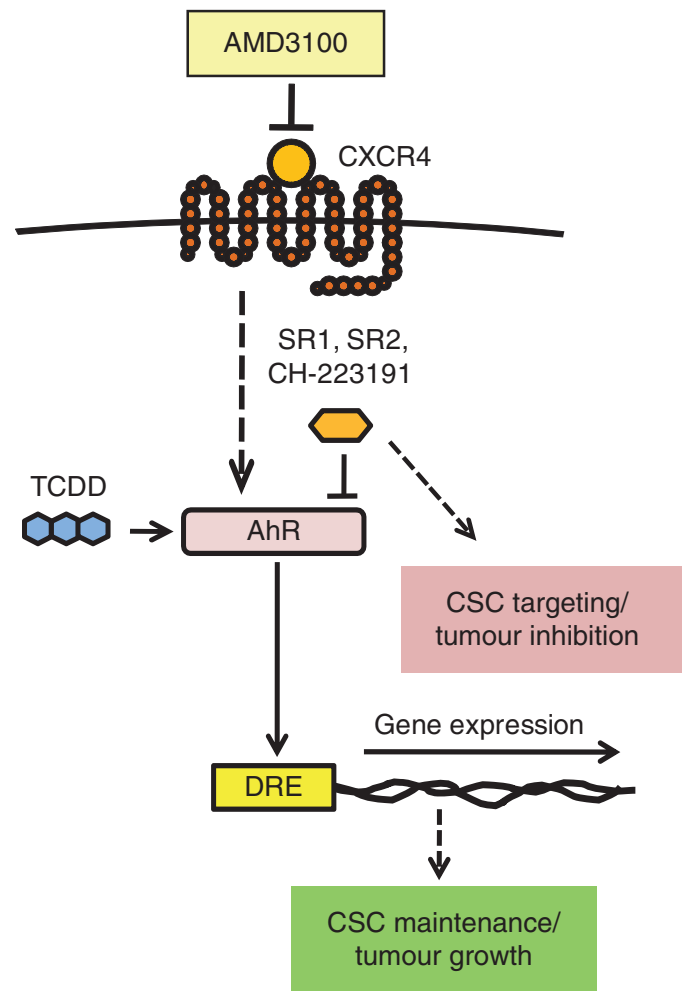

Figure 5 Mechanism of CXCR4-dependent maintenance of prostate cancer progenitors in tamoxifen-resistant MCF7 cells. CXCL4 signalling induces the activation of AhR-dependent gene transcription contributing to expanded progenitor population and tumour growth. Targeting CXCR4 signalling with small molecule inhibitors may be beneficial in eliminating prostate cancer stem-like cells in tamoxifen-resistant tumours.

receptor function (Wong and Chen, 2009). We showed that small molecule antagonists of AhR signalling could specifically target tamoxifen-resistant breast cancer progenitors and inhibit growth of tamoxifen-resistant tumours.

In conclusion, we report that tamoxifen-resistant cell populations harbour a higher percentage of tumour-initiating cells and that these cells are phenotypically altered compared with wild-type breast cancer cells. Furthermore, inhibition of CXCR4 or AhR with small molecule antagonists specifically target cancer stem-like cell populations in MCF7(TAM-R) cells and could be beneficial for the treatment of tamoxifen-resistant breast cancers (Figure 5). Further characterisation of the role of CXCR4 for AhR and ER signalling crosstalk will provide insight into new signalling pathways, which are involved in breast cancer progression.

\section{ACKNOWLEDGEMENTS}

We thank Margaret Chadwell for her support with immunohistochemical staining and Christopher Trussel for his technical assistance with flow cytometry. We are greatly indebted to $\mathrm{Dr}$ Kenneth P Nephew, Indiana University for supply of MCF7 and MCF7(TAM-R) cells. This study was supported by Susan G Komen for the Cure Grant PDF0707903 to A Dubrovska, the Novartis Research Foundation, and the Skaggs Institute for Chemical Biology.

Supplementary Information accompanies the paper on British Journal of Cancer website (http://www.nature.com/bjc) 


\section{REFERENCES}

Bouchez LC, Boitano AE, de Lichtervelde L, Romeo R, Cooke MP, Schultz PG (2011) Small-molecule regulators of human stem cell self-renewal. ChemBioChem 12(6): 854-857

Bunting KD (2002) ABC transporters as phenotypic markers and functional regulators of stem cells. Stem Cells 20(1): 11-20

Burger JA, Burger M, Kipps TJ (1999) Chronic lymphocytic leukemia B cells express functional CXCR4 chemokine receptors that mediate spontaneous migration beneath bone marrow stromal cells. Blood 94(11): 3658-3667

Charafe-Jauffret E, Ginestier C, Birnbaum D (2009) Breast cancer stem cells: tools and models to rely on. BMC Cancer 9: 202

Clark AS, West K, Streicher S, Dennis PA (2002) Constitutive and inducible Akt activity promotes resistance to chemotherapy, trastuzumab, or tamoxifen in breast cancer cells. Mol Cancer Ther 1(9): 707-717

Darash-Yahana M, Pikarsky E, Abramovitch R, Zeira E, Pal B, Karplus R, Beider K, Avniel S, Kasem S, Galun E, Peled A (2004) Role of high expression levels of CXCR4 in tumor growth, vascularization, and metastasis. FASEB J 18(11): 1240-1242

Dean M (2009) ABC transporters, drug resistance, and cancer stem cells. $J$ Mammary Gland Biol Neoplasia 14(1): 3-9

Delort L, Satih S, Kwiatkowski F, Bignon YJ, Bernard-Gallon DJ (2010) Evaluation of breast cancer risk in a multigenic model including low penetrance genes involved in xenobiotic and estrogen metabolisms. Nutr Cancer 62(2): 243-251

Dhingra K (1999) Antiestrogens - tamoxifen, SERMs and beyond. Invest New Drugs 17(3): 285-311

Doyle LA, Ross DD (2003) Multidrug resistance mediated by the breast cancer resistance protein BCRP (ABCG2). Oncogene 22(47): 7340-7358

Duan R, Porter W, Samudio I, Vyhlidal C, Kladde M, Safe S (1999) Transcriptional activation of $\mathrm{c}-$ fos protooncogene by 17beta-estradiol: mechanism of aryl hydrocarbon receptor-mediated inhibition. Mol Endocrinol 13(9): 1511-1521

Dubrovska A, Kim S, Salamone RJ, Walker JR, Maira SM, García-Echeverría C, Schultz PG, Reddy VA (2009) The role of PTEN/AKT/PI3K signaling in the maintenance and viability of prostate cancer stem-like cell populations. Proc Natl Acad Sci USA 106(1): 268-273

Dydensborg AB, Rose AA, Wilson BJ, Grote D, Paquet $\mathrm{M}$, Giguère $\mathrm{V}$, Siegel PM, Bouchard M (2009) GATA3 inhibits breast cancer growth and pulmonary breast cancer metastasis. Oncogene 28(29): 2634-2642

Engelmann K, Shen H, Finn OJ (2008) MCF7 side population cells with characteristics of cancer stem/progenitor cells express the tumor antigen MUC1. Cancer Res 68(7): 2419-2426

Epstein RJ (2004) The CXCL12-CXCR4 chemotactic pathway as a target of adjuvant breast cancer therapies. Nat Rev Cancer 4(11): 901-909

Fan M, Yan PS, Hartman-Frey C, Chen L, Paik H, Oyer SL, Salisbury JD, Cheng AS, Li L, Abbosh PH, Huang TH, Nephew KP (2006) Diverse gene expression and DNA methylation profiles correlate with differential adaptation of breast cancer cells to the antiestrogens tamoxifen and fulvestrant. Cancer Res 66(24): 11954-11966

Finlin BS, Gau CL, Murphy GA, Shao H, Kimel T, Seitz RS, Chiu YF, Botstein D, Brown PO, Der CJ, Tamanoi F, Andres DA, Perou CM (2001) RERG is a novel ras-related, estrogen-regulated and growth-inhibitory gene in breast cancer. J Biol Chem 276(45): 42259-42267

Furusato B, Mohamed A, Uhlén M, Rhims JS (2010) CXCR4 and cancer. Pathol Int 60(1): 497-505

Ginestier C, Hur MH, Charafe-Jauffret E, Monville F, Dutcher J, Brown M, Jacquemier J, Viens P, Kleer CG, Liu S, Schott A, Hayes D, Birnbaum D, Wicha MS, Dontu G (2007) ALDH1 is a marker of normal and malignant human mammary stem cells and a predictor of poor clinical outcome. Cell Stem Cell 1(5): 555-567

Gruvberger-Saal S, Bendahl PO, Saal LH, Laakso M, Hegardt C, Eden P, Peterson C, Malmstrom P, Isola J, Borg A, Ferno M (2007) Estrogen receptor $\beta$ expression is associated with tamoxifen response in ER $\alpha$ negative breast carcinoma. Clin Cancer Research 13(7): 1987-1994

Hadnagy A, Gaboury L, Beaulieu R, Balicki D (2006) SP analysis may be used to identify cancer stem cell populations. Exp Cell Res 312(19): 3701-3710

Hennessy BA, Harvey BJ, Healy V (2005) 17beta-Estradiol rapidly stimulates c-fos expression via the MAPK pathway in T84 cells. Mol Cell Endocrinol 229(1-2): 39-47

Huang M, Li Y, Zhang H, Nan F (2010) Breast cancer stromal fibroblasts promote the generation of CD44 + CD24- cells through SDF-1/CXCR4 interaction. J Exp Clin Cancer Res 29: 80

Hutcheson IR, Knowlden JM, Madden TA, Barrow D, Gee JM, Wakeling AE, Nicholson RI (2003) Oestrogen receptor-mediated modulation of the
EGFR/MAPK pathway in tamoxifen-resistant MCF7 cells. Breast Cancer Res Treat 81(1): 81-93

Hwang-Verslues WW, Kuo WH, Chang PH, Pan CC, Wang HH, Tsai ST, Jeng YM, Shew JY, Kung JT, Chen CH, Lee EY, Chang KJ, Lee WH (2009) Multiple lineages of human breast cancer stem/progenitor cells identified by profiling with stem cell markers. PLoS One 4: e8377

Johnson CD, Balagurunathan Y, Tadesse MG, Falahatpisheh MH, Brun M, Walker MK, Dougherty ER, Ramos KS (2004) Unraveling gene-gene interactions regulated by ligands of the aryl hydrocarbon receptor. Environ Health Perspect 112(4): 403-412

Korkaya H, Paulson A, Charafe-Jauffret E, Ginestier C, Brown M, Dutcher J, Clouthier SG, Wicha MS (2009) Regulation of mammary stem/progenitor cells by PTEN/Akt/beta-catenin signaling. PLoS Biol 7(6): e1000121

Lin SX, Chen J, Mazumdar M, Poirier D, Wang C, Azzi A, Zhou M (2010) Molecular therapy of breast cancer: progress and future directions. Nat Rev Endocrinol 6(9): 485-493

Lou H, Dean M (2007) Targeted therapy for cancer stem cells: the patched pathway and $\mathrm{ABC}$ transporters. Oncogene 26(9): 1357-1360

Mackay A, Urruticoechea A, Dixon JM, Dexter T, Fenwick K, Ashworth A, Drury S, Larionov A, Young O, White S, Miller WR, Evans DB, Dowsett M (2007) Molecular response to aromatase inhibitor treatment in primary breast cancer. Breast Cancer Res 9(3): R37

Maloof P, Wang Q, Wang H, Stein D, Denny TN, Yahalom J, Fenig E, Wieder R (1999) Overexpression of basic fibroblast growth factor (FGF-2) downregulates Bcl-2 and promotes apoptosis in MCF-7 human breast cancer cells. Breast Cancer Res Treat 56(2): 153-167

Mathieu MC, Lapierre I, Brault K, Raymond M (2001) Aromatic hydrocarbon receptor (AhR). AhR nuclear translocator- and p53mediated induction of the murine multidrug resistance mdrl gene by 3-methylcholanthrene and benzo(a)pyrene in hepatoma cells. J Biol Chem 276(7): 4819-4827

Normanno N, Di Maio M, De Maio E, De Luca A, de Matteis A, Giordano A, Perrone F (2005) Mechanisms of endocrine resistance and novel therapeutic strategies in breast cancer. Endocr Relat Cancer 12(4): 721-747

O'Brien CS, Howell SJ, Farnie G, Clarke RB (2009) Resistance to endocrine therapy: are breast cancer stem cells the culprits? J Mammary Gland Biol Neoplasia 14(1): 45-54

Pan J, Mestas J, Burdick MD, Phillips RJ, Thomas GV, Reckamp K, Belperio JA, Strieter RM (2006) Stromal derived factor-1 (SDF-1/CXCL12) and CXCR4 in renal cell carcinoma metastasis. Mol Cancer 5: 56

Pocar P, Fischer B, Klonisch T, Hombach-Klonisch S (2005) Molecular interactions of the aryl hydrocarbon receptor and its biological and toxicological relevance for reproduction. Reproduction 129(4): 379-389

$\mathrm{R}$ Development Core Team (2004) R: A language and environment for statistical computing. R Foundation for Statistical Computing, Vienna, Austria. ISBN 3-900051-07-0. http://www.R-project.org

Rebbeck TR, Troxel AB, Walker AH, Panossian S, Gallagher S, Shatalova EG, Blanchard R, Norman S, Bunin G, DeMichele A, Berlin M, Schinnar R, Berlin JA, Strom BL (2007) Pairwise combinations of estrogen metabolism genotypes in postmenopausal breast cancer etiology. Cancer Epidemiol Biomarkers Prev 16(3): 444-450

Rhodes LV, Short SP, Neel NF, Salvo VA, Zhu Y, Elliott S, Wei Y, Yu D, Sun M, Muir SE, Fonseca JP, Bratton MR, Segar C, Tilghman SL, SobolikDelmaire T, Horton LW, Zaja-Milatovic S, Collins-Burow BM, Wadsworth S, Beckman BS, Wood CE, Fuqua SA, Nephew KP, Dent P, Worthylake RA, Curiel TJ, Hung MC, Richmond A, Burow ME (2011) Cytokine receptor CXCR4 mediates estrogen-independent tumorigenesis, metastasis, and resistance to endocrine therapy in human breast cancer. Cancer Res 71(2): 603-613

Rosen JM, Jordan CT (2009) The increasing complexity of the cancer stem cell paradigm. Science 324(5935): 1670-1673

Singh S, Srivastava SK, Bhardwaj A, Owen LB, Singh AP (2010) CXCL12CXCR4 signalling axis confers gemcitabine resistance to pancreatic cancer cells: a novel target for therapy. Br J Cancer 103(11): 1671-1679

Swedenborg E, Pongratz I (2010) AhR and ARNT modulate ER signaling. Toxicology 268(3): 132-138

Vandercappellen J, Van Damme J, Struyf S (2008) The role of CXC chemokines and their receptors in cancer. Cancer Lett 267(2): 226-244

Wong C, Chen S (2009) Heat shock protein 90 inhibitors: new mode of therapy to overcome endocrine resistance. Cancer Res 69(22): 8670-8677

Wu C, Alman BA (2008) Side population cells in human cancers. Cancer Lett 268(1): 1-9 
Xie L, Wei J, Qian X, Chen G, Yu L, Ding Y, Liu B (2010) CXCR4, a potential predictive marker for docetaxel sensitivity in gastric cancer. Anticancer Res 30(6): 2209-2216

Yiangou C, Gomm JJ, Coope RC, Law M, Luqmani YA, Shousha S, Coombes RC, Johnston CL (1997) Fibroblast growth factor 2 in breast cancer: occurrence and prognostic significance. Br J Cancer 75(1): 28-33

Zeng Z, Samudio IJ, Munsell M, An J, Huang Z, Estey E, Andreeff M, Konopleva M (2006) Inhibition of CXCR4 with the novel RCP168 peptide overcomes stroma-mediated chemoresistance in chronic and acute leukemias. Mol Cancer Ther 5(12): 3113-3121

Zhou J, Wulfkuhle J, Zhang H, Gu P, Yang Y, Deng J, Margolick JB, Liotta LA, Petricoin 3rd E, Zhang Y (2007) Activation of the PTEN/ mTOR/STAT3 pathway in breast cancer stem-like cells is required for viability and maintenance. Proc Natl Acad Sci USA 104(41): 16158-16163

Zhou Y, Eppenberger-Castori S, Eppenberger U, Benz CC (2005) The NF kappa B pathway and endocrine-resistant breast cancer. Endocr Relat Cancer Suppl 1: S37-S46

Zlotnik A (2008) New insights on the role of CXCR4 in cancer metastasis. J Pathol 215(3): 211-213

This work is published under the standard license to publish agreement. After 12 months the work will become freely available and the license terms will switch to a Creative Commons Attribution-NonCommercial-Share Alike 3.0 Unported License. 